\title{
Measuring Volatility of Inflation in Pakistan
}

\section{Nadia Saleem ${ }^{*}$}

\begin{abstract}
The available evidence in Pakistan suggests that inflation is a monetary phenomena. This paper examines the relationship between the determinants of inflation and its volatility by using monthly data for 1990:M1-2007:M5. The determinants of inflation are estimated by a VAR analysis, which shows that inflation, the interest rate and money supply move together. A VAR model assumes constant error variance. We relaxed this assumption by employing an ARCH/GARCH model and conclude that inflation is volatile in nature. For measuring the qualitative nature of the inflationary process we used an EGARCH model. It confirms that the time effect model is significant. It also suggests that in the first four months of the calendar year, the inflationary shock is negative and it can, therefore, hamper growth.
\end{abstract}

JEL Classification: C01, E31, E51.

Keywords: Inflation, Volatility, Pakistan, Money Supply, Interest Rate.

\section{Introduction}

This paper sets out to explain that inflation emerges from permanent factors (measured) and transitory factors (unmeasured and temporary). Measured inflation is mainly due to monetary variables which the central bank can control to a certain extent but the transitory nature of inflation is unmeasured and a source of uncertainty. This transitory part consists of shocks like oil price hikes. These shocks are beyond the control of the central bank. This gives rise to uncertainty, which is the source of volatility and thus leads to less credible monetary policy. Inflation has a shoe leather cost, which affects resource allocation: it distorts market incentives and reduces efficiency: it can also destabilize governments for failing to control prices. Price hikes are one of the causative factors of changes in central bank policies. Central banks are no more able to give priority to any other objective over price stability. Therefore, there is a need to understand the dynamic nature of inflation in

\footnotetext{
* Assistant Professor, Department of Economics, GC University, Lahore.
} 
the first instance and then the role of volatility as it gives misleading signals to policy makers and economic agents.

Money is responsible for inflation but disagreement exists among economists on the role of money and its impact on the economy. Classical economists believed in the predominance of the transaction motive to hold money and the central bank exogenously determining money supply which has no impact on the real side of the economy. Money is thus considered no more than a veil and what has come to be known as the classical dichotomy prevailed. Prices changed but only with the change in money stock. No relationship exists between money supply and interest rates which are determined in the loanable funds market (saving and investment). Keynesians refute the dichotomy and believe in a negative relationship between money supply and the interest rate due to the indirect effect of unemployment. They emphasize the liquidity effect. Increased money supply affects the demand for liquidity and hence generates inflation and decreases the interest rate. According to them, increased government expenditure and lower taxes are responsible for inflation. Further, they dismiss the idea that shocks can generate inflation in the long run. The Monetarists believe that an increase in money supply shifts the aggregate demand, which increases output and decreases the unemployment rate below the natural rate of unemployment and increases the wage rate. The increased wage rate results in a decrease in demand for labor, which shifts the aggregate supply curve leftward. If this process continues in subsequent years, the economy will experience higher and higher inflation. In this way, Monetarists not only accept the liquidity effect but also the price effect and the income effect of demand for money. The role of the interest rate is no more dependent on money supply but on the demand for money. When the central bank decreases the money supply, it will result in an increase in the interest rate in the first instance. This will lead to a decrease in money demand in response and what happens to the interest rate in the end is indeterminate and depends on the income effect, wealth effect, inflation rate, and expectations (Mishkin, 1989).

According to Friedman (1977), upward movements in the price level are a monetary phenomenon only if this is a sustained process. Keynes and the Monetarists are agreed on the proposition that money alone is to blame for inflation and the interest rate appears as an integrating factor between the financial side and the real side of the economy. They emphasized the wealth effect, income effect and price effect.

Due to the instability and unpredictability of money demand, central bankers are using the interest rate to cut down inflationary expectations and 
the current inflation rate. The first time that inflation was targeted explicitly was towards the end of the 1980s by New Zealand. In this policy, an independent central bank uses the interest rate instead of money demand as an anchor for an exclusive focus on inflation. A direct relationship between the rate of inflation and the rate of interest enables investors to forecast the future inflation rate in case inflation deviates from the target.

This paper is divided as follows. In the next section, we review the literature related to the dynamics of inflation and empirical findings on the subject. The third section will provide the theoretical framework on the subject. Empirical results are in the fourth section. The last section presents conclusions drawn from the research.

\section{Literature Review}

In Mishkin and Posen (1997), price stability is stated as the primary goal of monetary policy. The authors make this conclusion by considering costs of inflation. An obvious cost of inflation is that people use non-interest bearing money because inflation could offset their interest income.

In the economic literature, views differ widely on the causes of inflation. The contemporary debate on inflation started with the monetarists' belief that money supply is the source of inflation, in contrast to the Keynesians' emphasis on structural factors. Post-Keynesians agreed with the findings of the monetarists but maintained that increased money supply was a necessary condition of inflation but not a cause of it. According to Zimmermann (2003), New Keynsians believe that the "economic shocks" caused by "nominal rigidities" and prevalence of "involuntary unemployment" are the reasons for inflation in the economy. They support rule-based polices for controlling inflation and the efficacy of monetary policy.

Friedman (1977) argues that inflation uncertainty is costly since it distorts relative prices and increases risk in nominal contracts. As inflation becomes highly unpredictable, investment and growth slow down. He further postulates that output growth is adversely affected by the volatility of inflation because increasing volatility makes it difficult for consumers to determine relative prices accurately. In addition, inflation volatility makes long term contracts more costly and thus less attractive. In either case, economic efficiency is reduced, subsequently retarding economic growth.

Engle (2004) constructed ARCH models to answer the unpredictability of inflation: "the original idea was to find a model that could assess the validity of the conjecture of Friedman (1977) that the 
unpredictability of inflation was a primary cause of business cycles. Uncertainty due to this unpredictability would affect the investors' behavior. Pursuing this idea required a model in which this uncertainty could change over time”.

Neyapti (2000) shows that inflation significantly raised uncertainty. Evidence in Nas and Perry (2000) supports this finding, while the evidence on the effect of inflation uncertainty on the level of inflation is mixed and depends on the time period analyzed. They used the EGARCH technique for modeling inflation uncertainty.

GARCH models not only allow the incorporation of the effects of the conditional mean into the system but also "accommodate the effects of the inflation shock on inflation volatility, and, in turn, the effects of inflation volatility on economic activity," (Elder, 2003).

To recapitulate, inflation emerges from monetary sources and the presence of nominal rigidities, and an unclear policy stance not only generates inflationary expectations but also triggers uncertainty. Not only is there a need to control the inflation rate due to its impact on economic growth but also to decrease volatility. Inflation increases volatility and uncertainty. This volatility again generates inflation due to wrong decision making by individuals. There is thus a two-way link between inflation and volatility.

In the Pakistani context, most authors conclude that money is the most significant cause of inflation in Pakistan. Our judgment that inflation in Pakistan is a monetary phenomena, originates from various empirical studies. Qayyum (2007) tested the monetarist proposition and presented findings that 90 percent of the variation in inflation was due to easy monetary policy adopted by the State Bank of Pakistan. Madhavi and Schimmelpfennig (2005) found that broad money growth and private sector credit growth helped explain inflation in Pakistan. Mubarik (2005), Jones and Khilji (1988), Khan and Siddiqui (1990), Bengali, et. al. (1997), and Hussain and Tariq (1997) all tried to find long run determinates of inflation in Pakistan. They emphasized that inflation is a monetary phenomenon $^{1}$.

\footnotetext{
${ }^{1}$ There are some studies which conclude that inflation is structural in nature. Khan and Qasim (1996) find food inflation to be driven by money supply, value-added in manufacturing, and the wheat support price. Khalid (2005) suggested that "imported inflation, seigniorage and openness cause inflation in Pakistan."
} 
This type of conclusion leads the discussion towards the role of the State Bank of Pakistan in controlling inflation and the influence of money in the real sector. These authors measured the determinants of inflation, which are either monetary variables or structural variables, but no study measured the impact of unobservable shocks and volatility on the inflation rate. This study aims to explore the dynamic nature of inflation and applies the VAR methodology to finding the relationship between the Consumer Price Index (CPI), broad money supply output and the lending rate.

\section{Model, Data and Econometric Methodology}

\subsection{Model Specification}

We use the model given by Soderstorm (1999), who criticized Sevensson (1997) for ignoring the explicit interest rate equation in the model and showed that this omission results into a more aggressive policy prescription. According to the author, the central bank cannot afford the aggressive policy for controlling inflation because of the inverse relationship between interest rate and investment. We modified their model by introducing the broad money supply equation along with CPI, Y (output), and LR (loan rate). This explicit money supply equation in the model will enable us to comment on the inflationary process and reduce volatility because the State Bank is using monetary aggregates for controlling inflation. We used an unstructured generalized VAR model for determining the inflationary process in Pakistan. Once we are able to estimate the nature of the inflation process in Pakistan we will further estimate volatility in the inflation rate because it generates uncertainty. In a high inflationary environment, individuals respond differently than in normal circumstances. There is no definitive judgment available as to why in certain time periods increases in money supply generate more negative effects as compared to normal time periods. The answer may lie in expectations or underdeveloped, less integrated markets. This riddle requires deeper investigation of inflation and money supply dynamics. It is important because several studies have shown that volatility increases uncertainty which badly affects macroeconomic stability.

Vector auto regressive models assume constant error variance, providing dubious results. What happens to the results if inflation is volatile in nature or if inflationary shocks are GARCH in nature? The present paper offers insights on inflation in Pakistan and measures the sources of volatility by using ARCH/GARCH and EGARCH techniques. 


\subsubsection{Vector Auto Regressive Model}

We use vector auto regressions and impulse response functions to show the relationship between broad money supply (M2), the consumer price index (CPI) output (IP) and the call money rate (CM). It will enable us to analyze the impact of money supply on inflation and the call money rate. We will further explore how a shock in one of the variables influences the time behavior of other variables. It will also allow us to study the role of the interest rate as a nominal target in Pakistan. (See Appendix 1 for details of the VAR and ARCH/ GARCH models.)

\subsubsection{Exponential GARCH Model}

Engle (1982) and Bollerslev (1986) developed the ARCH/GARCH models, which allow incorporation of the time varying nature of the variables. Furthermore, volatility in inflation is negatively related to economic growth. Nelson (1991) proposes an extended version of GARCH type models: the Exponential Generalized Auto Regressive Conditional Heteroscedastic (EGARCH). The EGARCH method has several advantages compared to both ARCH and GARCH methods to model inflation uncertainty for the following reasons. First, it allows for asymmetry in the responsiveness of inflation uncertainty to the sign of shocks to inflation. Secondly, unlike the GARCH specification, the EGARCH model, specified in logarithms, does not impose non-negativity constraints on parameters. Finally, modeling inflation and its uncertainty in logarithms hampers the effects of outliers on the estimation results. The EGARCH model has been commonly used to examine inflation rates, interest rates, exchange rates and to analyze stock returns (Brunner and Simon, 1996; Tse and Booth, 1996). Following Berument and Malatyali (2001) we model inflation by using lagged inflation and monthly seasonal dummies to account for seasonality:

$$
\Pi_{t}=\sum_{i=1}^{n} \alpha_{i} \Pi_{t-1}+\sum_{i=1}^{12} \delta_{\mathrm{i}} m_{i t}+\lambda D_{12}+\varepsilon_{t}
$$

In $\mathrm{Eq}(1 \mathrm{a}) \Pi_{t}$ represents inflation and $m_{i t}$ stands for the monthly dummies $(i=1,2 \ldots, 12)$ that account for monthly seasonal effects;

$$
\operatorname{Logh}_{t}^{2}=\beta_{o}+\beta_{1} \frac{\left|\varepsilon_{t-1}\right|}{h_{t-1}}+\beta_{2} \frac{\varepsilon_{t-1}}{h_{t-1}}+\beta_{3} \operatorname{Logh}_{t-1}^{2}+\lambda_{1} D_{12}
$$


Equation $1 \mathrm{~b}$ is the EGARCH representation of the conditional variance of inflation at time $t . \varepsilon_{\mathrm{t}}$ follows the usual white noise assumptions of zero mean and constant variance. $\left|\varepsilon_{\mathrm{t}-1}\right| / \mathrm{h}_{\mathrm{t}-1}, \varepsilon_{\mathrm{t}-1} / \mathrm{h}_{\mathrm{t}-1}$ follow the standard normal distribution. $\left|\varepsilon_{\mathrm{t}-1}\right| / \mathrm{h}_{\mathrm{t}-1}, \varepsilon_{\mathrm{t}-1} / \mathrm{h}_{\mathrm{t}-1}$ and the $\log$ of the lagged value of the conditional variance $\left(\mathrm{h}_{\mathrm{t}}^{2}\right)$ are used to explain the behavior of the conditional variance. $\beta_{2}$ represents the impact of good news or bad news. For good news it is greater than one and for bad news it is less than zero.

\subsection{Data Sources and Methodology}

The aim of the analysis is to build a statistical model that would link such macroeconomic variables such as the CPI to the growth rate in broad money supply (M2) and the call money rate (as a proxy for the interest rate). For ensuring a large sample size and for modeling sufficient variability, we used monthly data series of these aggregates from 1990:01 to 2007:07. The monthly data series (of 1990 M1-2007 M5) is obtained from International Financial Statistics (IFS) (2007) and from the web site www.statpak.gov.pk/depts/index.htm, Federal Bureau of Statistics, Government of Pakistan. Annual data series (1970-2007) is obtained from the World Development Indicators (2007).

\subsubsection{Variables and Definitions}

Broad Money Supply (M2): The broad money (M2) consists of M1, time deposits and resident foreign currency deposits with the scheduled banks. This implies that M2 takes into account not only those financial assets which can directly be used as a medium of exchange but are also close substitutes of liquid assets (State Bank of Pakistan, 2008).

Consumer Price Index (CPI): The CPI is the most relevant tool of measuring inflation in consumer items. The Federal Bureau of Statistics regularly collects price statistics resulting in the monthly release of a Consumer Price Index (Federal Bureau of Statistics, 2008).

Call Money Rate (CM): Call money generally refers to secured or unsecured 'at-call' loans made by banks to money market dealers. According to the State Bank of Pakistan, interbank clean (without collateral) lending/borrowing rates are referred to as Call Money Rates (State Bank of Pakistan, 2008).

Industrial Product (IP): Large scale manufacturing index is used as proxy for measuring output (International Financial Statistics, 2007). 


\section{Analysis and Results}

\subsection{Inflation Dynamics: Overview of Pakistan's Economy}

Inflation in Pakistan has not received serious attention from government policy makers, although price stability is one of the basic policy objectives of the State Bank of Pakistan. The inflation rate had been historically low. A mere 3.3 percent in the 1960s, it rose to 11.9 percent on average in the 1970s due to oil shocks which destabilized all economies, and fell again to an average of only 7.5 percent in the 1980s. Since the 1990s inflation became a matter of some concern. The recent high inflation rate has attracted the attention of a number of economists in Pakistan. Rapid increases in world oil and commodity prices, wheat shortages, mounting fiscal deficits and increased bank borrowing are considered the main reasons for inflation in the economy.

The GDP growth rate remained below 5 percent until the late 1970 s during which inflation remained in mostly double digits. On average it could be suggested that the growth performance was dismal in the years of double digit inflation rate in Pakistan. The lowest observed rate of inflation in 1986 was preceded by a very high growth rate in 1985 . In the 1990 s the inflation rate was in double digits and the economy experienced poor growth. It may, therefore, be suggested that high inflation is one of the causative factors for low growth rate in the economy but we cannot generalize it.

For observing trends in the Consumer Price Index (CPI), broad money supply (M2) Gross Domestic Product (GDP) and Market Exchange Rate(MXR) we plot the log series against time. The line graphs show an upward trend during the period of 1970-2007. An important conclusion which can be drawn is that inflation, money supply, nominal exchange rate and output series are positively related (Appendix 2). 
Table-1: Descriptive Statistics for the Growth Rate of Broad Money

Supply, Inflation Rate, Depreciation Rate and Call Money Rate (1990:M1-2007:M5)

\begin{tabular}{lccccc}
\hline Statistics & $\begin{array}{c}\text { Call } \\
\text { Money } \\
\text { Rate }\end{array}$ & $\begin{array}{c}\text { Depreciation } \\
\text { Rate }\end{array}$ & $\begin{array}{c}\text { Inflation } \\
\text { Rate }\end{array}$ & $\begin{array}{c}\text { Growth Rate } \\
\text { in Broad } \\
\text { Money Supply }\end{array}$ & $\begin{array}{c}\text { Annual } \\
\text { GDP } \\
\text { Growth } \\
\text { Rate }\end{array}$ \\
\hline Mean & 8.49 & 0.58 & 7.24 & 4.92 & 5.37 \\
Maximum & 18.37 & 8.48 & 20.35 & 905.79 & 11.4 \\
Minimum & 0.74 & -2.38 & 0.06 & -90.04 & 0.468 \\
Skewness & -0.03 & 2.68 & 0.27 & 14.61 & 0.056 \\
Kurtosis & 2.42 & 11.30 & 2.55 & 217.23 & 2.87 \\
Std. Dev. & 3.86 & 1.47 & 3.84 & 60.79 & 2.49 \\
\hline
\end{tabular}

Table-1 shows that the inflation rate, call money rate and growth rate in money supply are highly volatile, having very high standard deviations compared to GDP. In a managed floating exchange rate regime, the role of monetary policy is limited as it is subservient to the import transmitting countries' exchange rate. So we ignored the exchange rate in the discussion. According to the information in Table-1, CPI and the growth rate in broad money supply are highly volatile series.

\subsection{Empirical Results of Unrestricted VAR}

For estimating the unrestricted Vector Auto Regressive (VAR) model, the order of integration of all the endogenous variables is needed. In this paper we apply tests such as Augmented Dickey-Fuller (ADF) on the level data of Consumer Price Index (CPI), broad money supply (M2), output (Y) and lending rate (LR). All the variables are integrated with order one, d(1). Max lag length is 2, determined on the basis of the Schwarz Information Criterion. As it is monetary data, we prefer short lag lengths. As the data used in VAR is non-stationary, we use a first difference VAR model. It explains the short run dynamic relationship between the data. We started with the theoretical debate that inflation is a monetary phenomenon and it can be controlled through nominal anchors.

The results in Table-2 show that CPI is positively related to the call money rate for both lags but is insignificant. CPI is positively associated with previous lags of CPI and it is significant. CPI is positively related to output at the first lag and negatively related to output at the second lag which 
makes the case that inflation hampers growth but again it is insignificant at both lags. CPI is positively related to the broad money supply at both lags which confirms that inflation is a monetary phenomena; an increase in money supply results in ab increase in the inflation rate but the results are again insignificant.

Table-2: VAR Regression Results (1990: M1-2007:M5)

\begin{tabular}{lcccc}
\hline & $\boldsymbol{C P I}$ & $\boldsymbol{I P}$ & $\boldsymbol{M} 2$ & $\boldsymbol{C M}$ \\
\hline CM Lag 1 & 0.03193 & -0.37567 & 0.036527 & 0.53689 \\
t ratios & {$[0.77506]^{*}$} & {$[-1.43372]$} & {$[0.92027]^{*}$} & {$[7.81212]$} \\
CM Lag 2 & 0.023324 & 0.381535 & 0.11527 & 0.184558 \\
t ratios & {$[0.56553]^{*}$} & {$[1.45439]$} & {$[2.90074]$} & {$[2.68229]$} \\
CPI Lag 1 & 0.544396 & 0.322265 & 0.03706 & 0.03162 \\
t ratios & {$[8.51346]$} & {$[0.79230]$} & {$[0.60147]^{*}$} & {$[0.29640]^{*}$} \\
CPI Lag 2 & 0.445756 & -0.07228 & 0.024679 & -0.04005 \\
t ratios & {$[6.98358]$} & {$[-0.17803]$} & {$[0.40127]^{*}$} & {$[-0.37610]^{*}$} \\
IP Lag 1 & 0.007317 & 0.848674 & $-5.05 \mathrm{E}-05$ & 0.047227 \\
t ratios & {$[0.68223]^{*}$} & {$[12.4401]$} & {$[-0.00489]^{*}$} & {$[2.63935]$} \\
IP Lag 2 & -0.002418 & -0.036 & 0.003396 & -0.04758 \\
t ratios & {$[-0.22696]^{*}$} & {$[-0.53132]$} & {$[0.33079]^{*}$} & {$[-2.67720]$} \\
M2 Lag 1 & 0.00919 & 2.17436 & -0.12586 & -0.12525 \\
t ratios & {$[0.13046]^{*}$} & {$[4.85116]$} & {$[-1.85371]$} & {$[-1.06542]^{*}$} \\
M2 Lag 2 & 0.05583 & 1.796752 & -0.17805 & 0.072238 \\
t ratios & {$[0.76003]^{*}$} & {$[3.84551]$} & {$[-2.51566]$} & {$[0.58947]$} \\
C & 0.688695 & -5.8748 & 3.024172 & 3.105588 \\
t ratios & {$[1.17960]$} & {$[-1.58193]$} & {$[5.37578]$} & {$[3.18834]$} \\
Adj. R-squared & 0.996456 & 0.924929 & 0.059064 & 0.46633 \\
F-statistic & 7372.373 & 331.3104 & 35309.76 & 23.43933 \\
\hline & & & & \\
\hline
\end{tabular}

* Shows Insignificant Results

Money supply is positively related to the call money rate $(\mathrm{CM})$ at both lags. It is insignificant at the first lag and insignificant at the second 
lag. This fact sheds light that in Pakistan the income and price effect is stronger than the liquidity effect. This makes the case that money supply and the interest rate are moving in the same direction. When money supply increases, the quantity demanded for money increases in the first instance and results in a lower interest rate. If people expect more inflation and demand for money increases rapidly then the interest rate will also shoot up. The result that money supply and the interest rate are moving in the same direction suggests that there is strong demand for money (liquidity effect) in the economy. In this scenario we can infer that the inflation rate, interest rate and growth in money supply move together in Pakistan. The results of the VAR are insignificant, thus not reliable, and call for the further investigation of the inflation rate.

\subsubsection{Impulse Response Function}

An impulse response function traces the effect of a one-time shock to one of the variables on current and future values of the endogenous variables. It is the effect of an outside shock to a variable (Hamilton, 1994). If the value of impulse response function is positive and less then one, it means that the response dies down monotonically, approaching zero.

In figure 1, we present the impulse response graph. When a shock is generated from the call money rate to call money rate, it started with the value greater than zero but its response dies out to zero from the above. The response of call money to the CPI is fluctuating between positive and negative values but it is a convergent case and highly significant as it dies out to zero. The response of call money to broad money supply is also convergent and stable. The response of the CPI to a call money rate shock monotonically dies out and approaches zero, resulting in a stationary series. The response of CPI to CPI is divergent and it never dies out. This means that the CPI has an explosive impact on current CPI. A shock in form of broad money supply has a convergent affect on all the variables as the series dies out to zero, making it significant and stable. 
Figure 1: Impulse Response Function

Response to Cholesky One S.D. Innovations \pm 2 S.E
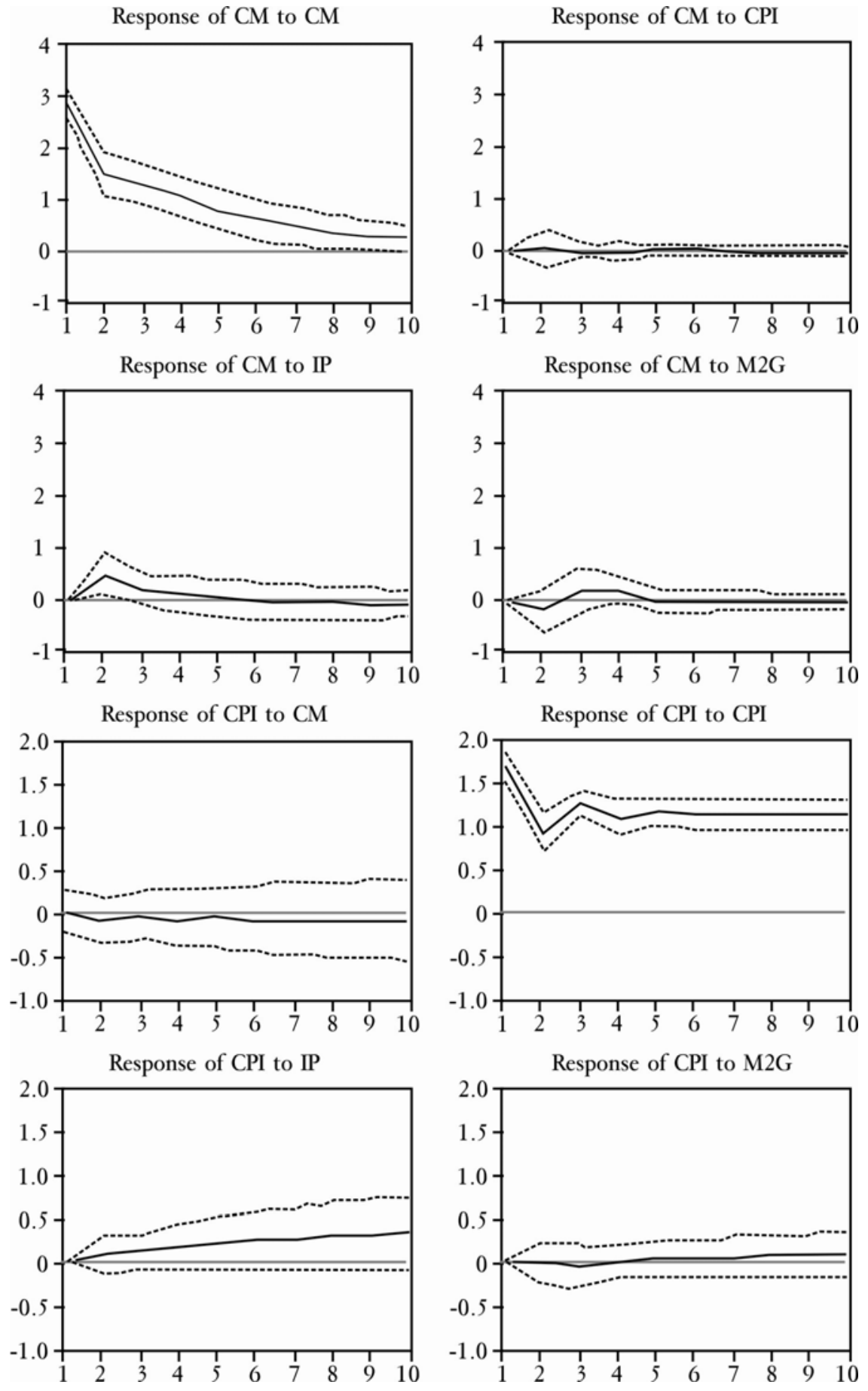

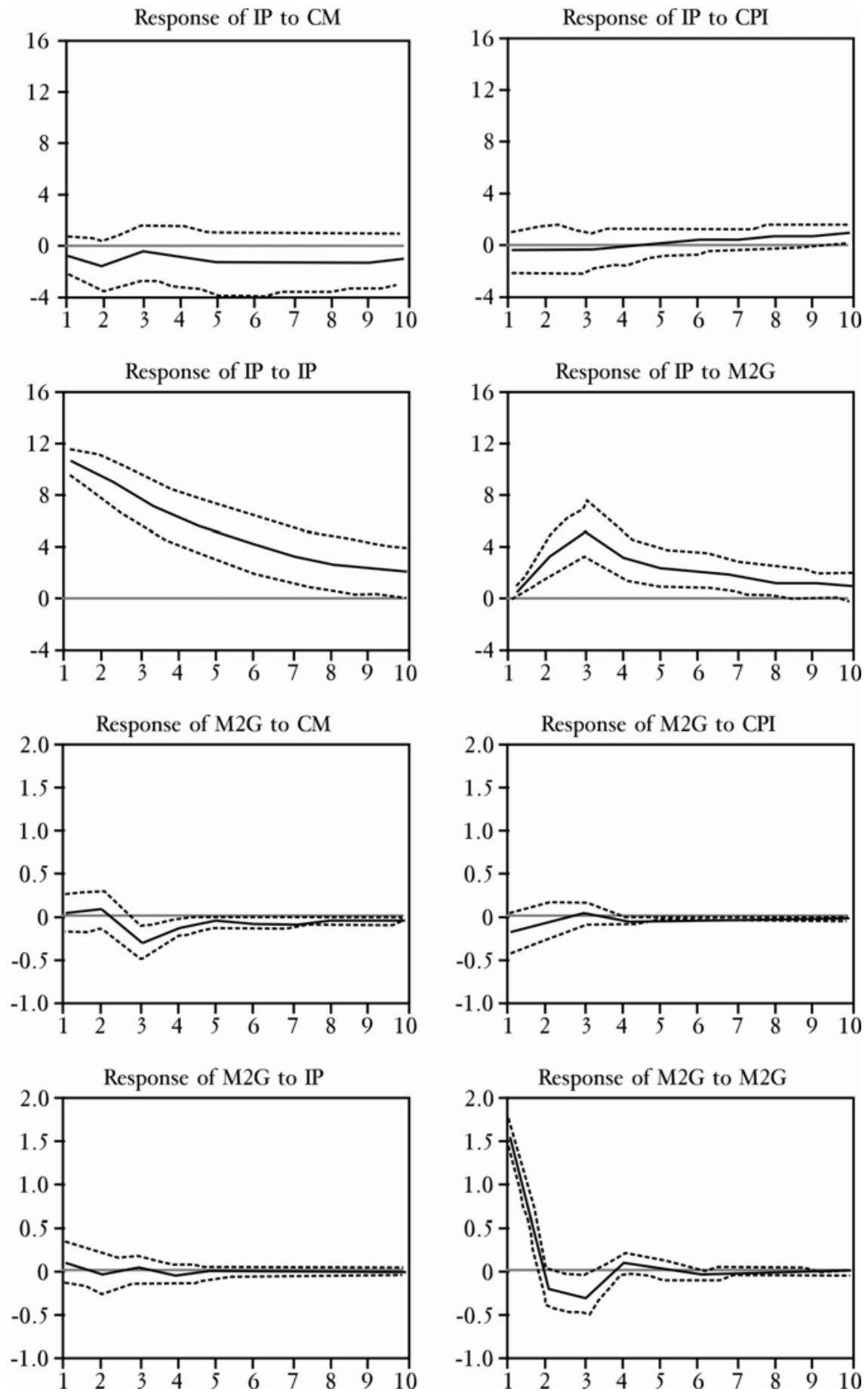


\subsection{Measuring Volatility in Inflation Rate}

VAR analysis helped us in measuring the permanent nature of inflation relations. Now we concentrate on the transitory nature of inflation volatility by employing a GARCH model so that we can relax the assumption of constant variance.

For modeling inflation rate we conduct the Augmented Dickey Fuller unit root test. It confirms that CPI data is not stationary. Thus we analyze the first difference of the series which is stationary. We use the first difference of the seasonally unadjusted CPI over the period 1990:1 to 2007:7. The first difference can damage the actual relationship but it can explain the short run relationship (Appendix -3).

\section{Pre- Estimation of ARCH/GARCH Effect:}

We compute the inflation rate from a seasonally unadjusted series of CPI and plot the series. As can be seen in Figure 2, it shows high volatility.

Figure-2: Monthly Inflation Rate of Pakistan

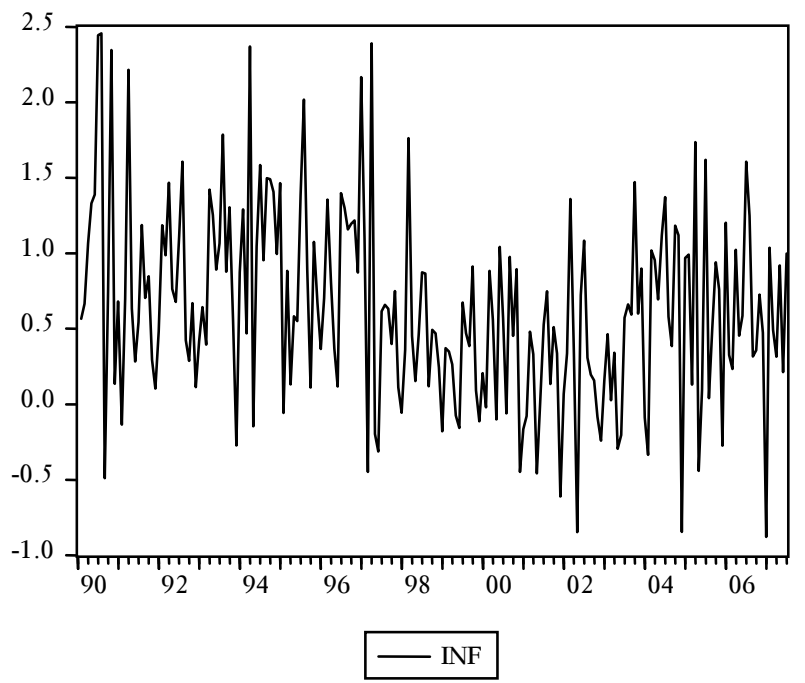

After conducting the unit root test and transforming a non-stationary series into a stationary one, we plotted the Auto Correlation Function (ACF) and Partial Auto Correlation Function of the series. From the correlogram we determined the order of AR model which showed maximum significance at 3 lags. This means that we have an Auto Regressive Integrated model ARI $(3,1)$. CPI has 3 months lag memory. The results obtained from ARI $(3,1)$ demonstrated that there is a feedback of inflation after 3 months which is significant and stable. The estimated coefficient of the lagged variable which 
measures inflation uncertainty is positive and statistically significant (Appendix-4).

$$
\mathrm{D}(\mathrm{cpi})=0.3686+0.2919 \mathrm{~d}(\mathrm{cpi}(-3))
$$

P-values

After estimating the univariate CPI series, we checked it for $\mathrm{ARCH}$ effects. There is significant serial correlation. It is evident that we can apply the ARCH technique for modeling inflation in Pakistan. We conducted the Engle ARCH test. This test also provided significant evidence in support of GARCH effects (i.e., heteroscedasticity).

ARCH LM Test

In order to confirm the ARCH effect in the CPI series we apply the ARCH LM test. It is significant. The ARCH-LM statistic cannot reject the null hypothesis that there is no ARCH effect for the standardized residuals up to the $36^{\text {th }}$ lag. (Appendix-5)

\subsubsection{Estimation of Variance Equation: (GARCH) $(1,1)$}

There is a positively significant relationship between the residuals which suggests increased volatility in the unanticipated rate of inflation.

$$
h_{t}=-0.0014+0.00157 \varepsilon_{t}^{2}+0.9122 h_{t-1}
$$

$$
(0.0012) \quad(0.0009) \quad(0.0084)
$$

P-Values $\quad(0.26) \quad(0.09) \quad(0.00)$

\section{Post Estimation Analysis}

The same Ljung-Box-Pierce Q-Test applies to the square residuals. It confirms there is no serial correlation and that there is no GARCH effect left.

QQ Plot

The QQ plot indicates that it is primarily large negative shocks that are driving the departure from normality. The plot shows that there are negative shocks which are causing the inflation rate to drift away from normality (Appendix -6). 


\subsection{EGARCH ModeI}

The presence of the negative shocks leads us to estimate the same model with time dummies. The parameters of the EGARCH model are measured on the basis of monthly time dummies. This model captures the impact of seasonal dummies and asymmetric information on the CPI as well as the impact of money supply, call money rate and industrial output. Therefore, we estimated a VAR model of the CPI. Given below is the mean equation of the model.

$$
\begin{aligned}
& \mathrm{CPI}=0.059+0.0028 \mathrm{CM}(-1)+0.0042 \mathrm{CM}(-2)+0.628 \mathrm{CPI}(-1)+0.383 \mathrm{CPI}(-2)- \\
& 0.0059 \mathrm{IP}(-1)+0.0046 \mathrm{IP}(-2)+0.0028 \mathrm{M} 2 \mathrm{G}(-1)+0.0177 \mathrm{M} 2 \mathrm{G}(-2)
\end{aligned}
$$

(Mean Equation)

$$
\operatorname{LOG}\left(\mathrm{h}_{\mathrm{t}}\right)=-0.347+0.638\left|\mathrm{e}_{\mathrm{t}-1}\right| \mathrm{h}^{2}{ }_{\mathrm{t}-1}-0.289 \mathrm{e}_{\mathrm{t}-1} / \mathrm{h}_{\mathrm{t}-1}^{2}+0.974 \log \mathrm{h}_{\mathrm{t}-1}^{2}
$$

(Variance Equation)

This equation is significant and the value of 0.974 confirms the presence of EGARCH on the data. The coefficient $-0.289<0$ shows the negative effect of the inflation. It means bad news generates more volatility as compared to good news. The impact of negative and positive shocks are asymmetric (Appendix-7).

Table-3: Fixed Effect Model

\begin{tabular}{cccc}
\hline Monthly Dummies & Fixed Effect & Monthly Dummies & Fixed Effect \\
\hline 1 & -0.707 & 7 & 0.001599 \\
2 & -0.01497 & 8 & 0.002192 \\
3 & -0.00881 & 9 & 0.003669 \\
4 & -0.00312 & 10 & 0.010343 \\
5 & 0.001232 & 11 & 0.01302 \\
6 & 0.001317 & 12 & 0.015309 \\
\hline
\end{tabular}

On the basis of the asymmetric effect of inflation we measured the time varying affect of the model by incorporating time dummies. The time dummies are significant and show that inflation in the first 4 months of the year can generate a negative shock to the model and that feedback exists for unanticipated inflation. Positive innovations show a decline of volatility. 


\section{Conclusion}

The main conclusion of the paper is that inflation is volatile in nature and this generates uncertainty in the economy. The significance of this feature of inflation is that uncertainty can affect growth adversely.

The analysis in this paper finds that inflation volatility is significantly and positively related to the level of inflation, which can generate uncertainty in the economy. Money supply is also volatile in nature.

Inflation volatility, as measured by the EGARCH mode1, robustly and significantly creates unanticipated negative shocks in the first four months of the calendar year. These negative shocks on the one hand can hamper growth and on the other hand explain that a time effect (seasonal effect) also exists in the case of inflation in Pakistan. If a shock in the first four months emerges it may be due to increased oil consumption (energy use increases in winter) as compared to the summer season. This is the time period when there may be food shortages, which is a causative factor of inflation. This phenomenon calls for further in-depth investigation.

Money supply is also found to be volatile in nature. There is significant evidence that it can generate shocks in inflation. An important feature to note is that there exists a feedback effect from broad money supply to inflation. VAR results show that inflation, money supply and the interest rate move into same direction. 


\section{References}

Bengali, K., Khan, A. and M. Sadaqat, 1997, "Money, Income, Prices, and Causality: The Pakistani Experience.” (Unpublished Paper)

Berument H., and Malatyali, K., 2001, "Determinants of Interest Rates in Turkey." Russian and East European Finance and Trade, Vo1. 59 : 347-370.

Bollerslev, T., 1986, "Generalized Autoregressive Conditional Heteroskedasticity.” Journal of Econometrics, Vo1. 31, 3 : 307-27.

Brunner, A. D. and Simon, D. P., 1996, "Excess Returns and Risk at the Long End of the Treasury Market: An EGARCH-M Approach.” Journal of Financial Research, Vo1. 19, 3 : 443-4.

Elder, J., 2003, "Another Perspective on the Effects of Inflation Uncertainty." Journal of Money, Credit and Banking, Vo1. 36 : $305-$ 311.

Engle, R. F., 2004, "The Use of ARCH/GARCH Models in Applied Econometrics." The Journal of Economic Perspectives, Vol. 15, 4 : 157-168.

Engle, R. F., 1982, "Autoregressive Conditional Heteroscedasticity with Estimates of the Variance of United Kingdom Inflation." Econometrica, Vol. 50, 4 : 83-106.

Federal Bureau of Statistics, 2008, www.statpak.gov.pk/depts/index.htm, Federal Bureau of Statistics - Government of Pakistan.

Friedman, M., 1970, “The Counter-Revolution in Monetary Theory." London: Institute of Economic Affair.

Friedman, M., 1977, “Nobel Lecture: Inflation and Unemployment.” Journal of Political Economy, Vo1. 85 : 451-472.

Government of Pakistan, Various Issues. Pakistan Economic Survey, Ministry of Finance, Islamabad, Pakistan.

Hamilton, J. D., 1994, Time Series Analysis, Princeton. 
Husain, F. and Mahmood, T., 1997, "Causality between Money and Prices: Evidence from Pakistan." The Pakistan Development Review, Vol. 37,3 (II) : 1155-1161.

International Financial Statistics (IFS), 2005, 2007, International Monetary Fund, Washington D.C.

Jones, J., and Khilji N., 1988, "Money Growth, Inflation, and Causality: Empirical Evidence for Pakistan 1973-85.” The Pakistan Development Review, Vo1. 28, $1:$ 45-58.

Khalid, A. M., 2005, "Economic Growth, Inflation, and Monetary Policy in Pakistan: Preliminary Empirical Estimates." The Pakistan Development Review, Vo1. 44, 4 (II) : 961-974.

Khan, A. H., and Siddiqui, A. N., 1990, "Money, Prices and Economic Activity in Pakistan: A Test of Causal Relation.” Pakistan Economic and Social Review : 121- 136.

Khan, A. H. and Qasim, M.A., 1996, "Inflation in Pakistan Revisited." The Pakistan Development Review, Vo1. 35, 4 (II) : 747 - 759.

Madhavi, Schimmelpfennig, A., 2005, “Three Attempts at Inflation Forecasting in Pakistan.” IMF Working Paper, Middle East and Central Asia Department.

Mishkin, F. S. Posen, A. S., 1997, "Inflation Targeting: Lessons from Four Countries.” NBER Working Paper, 6126.

Mishkin, F. S., 1989, The Economics of Money Banking and Financial Markets. Seventh Edition, Addison Wesley, Columbia University, New York.

Mubarik, Y. A., 2005, "Inflation and Growth: An Estimate of the Threshold Level of Inflation in Pakistan." State Bank of Pakistan, Working Paper, No. 8.

Nas, T. F. and Perry, M. J., 2000, "Inflation, Inflation Uncertainty and Monetary.” Contemporary Economic Policy. Vol. 18 : 170-180.

Nelson, D. B., 1991, "Conditional Heteroscedasticity in Asset Returns: A New Approach.” Econometrica, Vo1. 59, 2 : 347-370. 
Neyapti, B., 2000, "Inflation and Inflation Uncertainty in Turkey: Evidence from EGARCH Approach.” Econometrica, Vol. 59 : 147-155.

Qayyum, A., 2006, "Money, Inflation, and Growth in Pakistan." The Pakistan Development Review, Pakistan Institute of Development Economics, Vol. 45, 2 : 203-212.

Soderstorm, U., 1999, “Should Central Bank be More Aggressive?" Working Paper in Economics and Finance No. 309, Stockholm School of Economics, Sweden.

Svensson, L. E., 1997, "Inflation Forecast Targeting: Implementing and Monitoring Inflation Targets.” European Economic Review, Vol. 41 : 1111-47.

Tse, Y. and Booth, G. G., 1996, "Common Volatility and Volatility Spillovers between U.S. and Eurodollar Interest Rates: Evidence." Journal of Futures Markets, Vo1. 18 : 129-149.

World Development Indicators 2007, World Bank.

Zimmermann, G., 2003, "Optimal Monetary Policy: A New Keynesian View." The Quarterly Journal of Austrian Economics, Vo1. 6, 4 : 61-72. 


\section{Appendix-1}

\section{Vector Auto Regressive Models:}

When variables are not exogenously determined, $\mathrm{Yt}$ and $\mathrm{Xt}$ are affected by current value and past values of $\mathrm{Yt}$ and $\mathrm{Xt}$ simultaneously, where we assume Yt and Xt are stationary and error terms are uncorrelated. It constituted the first order VAR.

$$
\begin{aligned}
& {\left[\begin{array}{llll}
a_{11} & a_{12} & a_{13} & a_{14} \\
a_{21} & a_{22} & a_{23} & a_{24} \\
a_{31} & a_{32} & a_{33} & a_{34} \\
a_{41} & a_{42} & a_{43} & a_{44}
\end{array}\right]\left[\begin{array}{l}
C P I_{t} \\
L R_{t} \\
M 2_{t} \\
Y_{t}
\end{array}\right]=\left[\begin{array}{llll}
b_{11} & b_{12} & b_{13} & b_{14} \\
b_{21} & b_{22} & b_{23} & b_{24} \\
b_{31} & b_{32} & b_{33} & b_{34} \\
b_{41} & b_{42} & b_{43} & b_{44}
\end{array}\right] \quad\left[\begin{array}{l}
C P I_{t-1} \\
L R_{t-1} \\
M 2_{t-1} \\
Y_{t-1}
\end{array}\right]+\left[\begin{array}{l}
e_{1 t} \\
e_{2 t} \\
e_{3 t} \\
e_{4 t}
\end{array}\right]} \\
& \begin{array}{cllll}
A & Z_{t} & B & Z_{t-1} & u_{t}
\end{array}
\end{aligned}
$$

Matrix A in this equation shows contemporaneous response or immediate response of variables to changes in other variables. The relationship can be represented as follows:

$$
\mathrm{AZ}_{\mathrm{t}}=\mathbf{B Z} \mathrm{Z}_{\mathrm{t}-1}+\mathrm{U}_{\mathrm{t}}
$$

To run regressions one needs dependent variable on the left-hand side and independent variables on the right hand side. After rearranging:

$$
Z_{t}=A^{-1} B Z_{t-1}+A^{-1} U_{t}
$$

Now denote $A^{-1} B$ by $C$ and $A^{-1} U t$ by $W t$ to obtain the following regression:

$$
Z_{t}=C_{t-1}+W_{t}
$$

\section{ARCH/GARCH Models}

An autoregressive conditional heteroskedasticity (ARCH, Engle (1982)) model considers the variance of the current error term to be a function of the variances of the previous time period's error terms. ARCH relates the error variance to the square of a previous period's error.

He measured residuals as

$$
\varepsilon_{t}=y_{t}-\mu_{t}(y t)
$$


Where $\mathrm{y}_{\mathrm{t}}$ is an observable random variable. Engle assumed that $\varepsilon_{\mathrm{t}}$ can be decomposed as follows:

$$
\varepsilon_{t}=\chi_{t} h_{t}^{1 / 2}
$$

Where $\{x t\}$ is a sequence of independent, identically distributed (iid) random variables with zero mean and unit variance. ARCH modeling can be applied to a normal distribution or a leptokurtic distribution. The following conditional variance defines an ARCH model of order q:

$$
h_{t}=\alpha_{0}+\sum_{j=1}^{q} \alpha_{j} \varepsilon_{t-j}^{2}
$$

The parameter restrictions in the above equation form a necessary and sufficient condition for positivity of the conditional variance.

Bollerslev (1986) and Taylor (1986) proposed GARCH model independently of each other. They criticized use of squared residuals in variance equation is an obvious but not necessarily a very good solution for modeling conditional variance if data of higher frequency are available. In their model, the conditional variance is also a linear function of its own lags and has the form

$$
h_{t}=\alpha_{0}+\sum_{j=1}^{q} \alpha_{j} \varepsilon_{t-j}^{2}+\sum_{j=1}^{p} \beta_{j} h_{t-j}
$$

For the ARCH family, the decay rate is too rapid compared to what is typically observed in financial time series, unless the maximum lag $\mathrm{q}$ in ARCH variance equation is long. For avoiding this problem Nelson (1991) proposed EGARCH models. 


\section{Appendix-2}

Trend Analysis of Broad Money Supply, Inflation Rate, Nominal Exchange Rate and GDP (1970-2007) Annual Data.
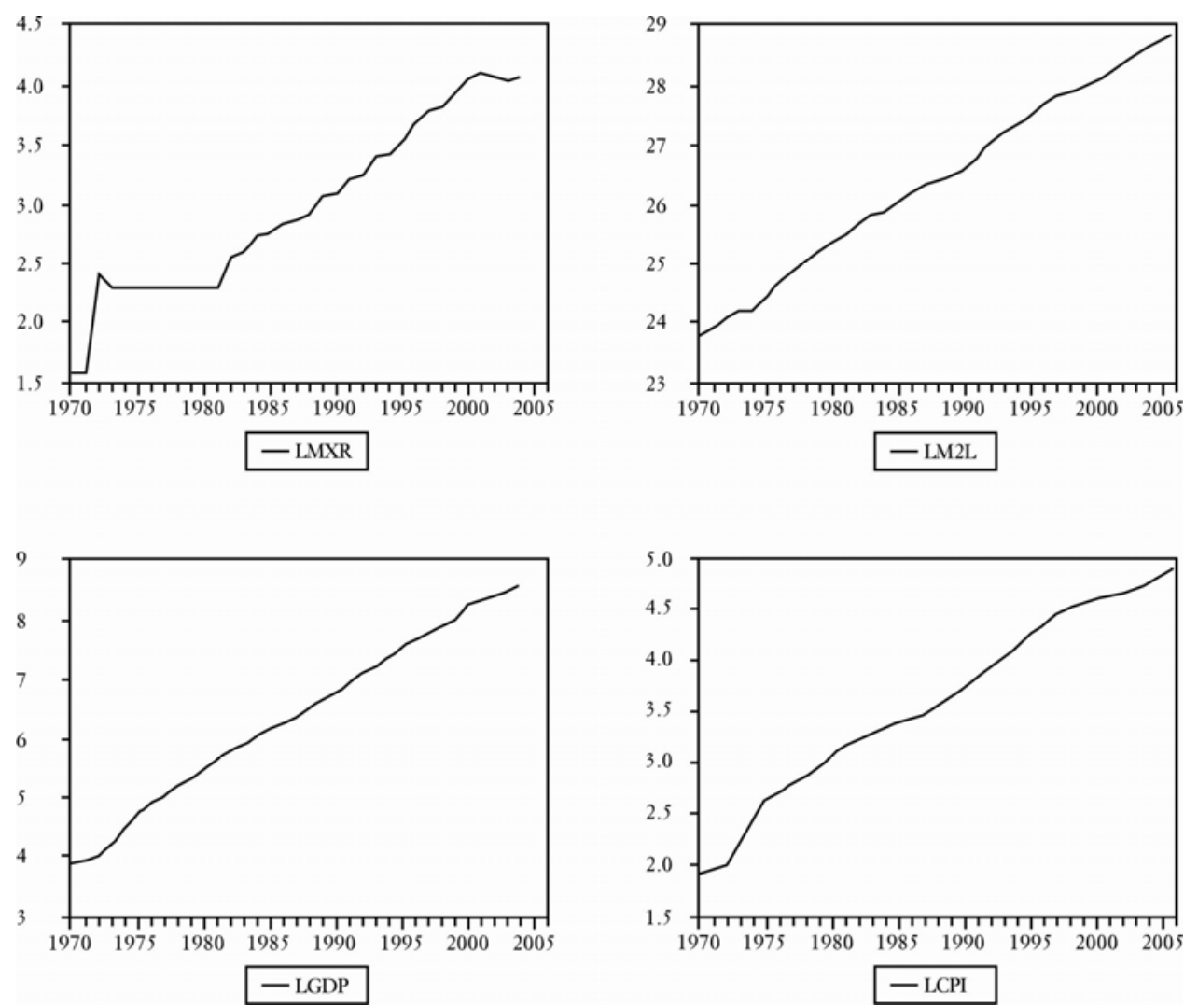


\section{Appendix-3}

\section{Unit Root Test}

Null Hypothesis: CPI has a unit root

Exogenous: Constant

Lag Length: 3 (Automatic based on SIC, MAXLAG=14)

\begin{tabular}{lccc}
\hline & & t-Statistic & Prob.* \\
\hline Augmented Dickey-Fuller test statistic & 1.197583 & 0.9981 \\
Test critical values: & 1\% level & -3.461938 & \\
& 5\% level & -2.875330 & \\
& 10\% level & -2.574198 & \\
\hline
\end{tabular}

Null Hypothesis: D(CPI) has a unit root

Exogenous: Constant

Lag Length: 2 (Automatic based on SIC, MAXLAG=14)

\begin{tabular}{lccc}
\hline & & t-Statistic & Prob.* $^{*}$ \\
\hline Augmented Dickey-Fuller test statistic & -6.265166 & 0.0000 \\
Test critical values: & 1\% level & -3.461938 & \\
& 5\% leve1 & -2.875330 & \\
& $10 \%$ level & -2.574198 & \\
\hline
\end{tabular}

*MacKinnon (1996) one-sided p-values.

Null Hypothesis: M2G has a unit root

Exogenous: Constant

Lag Length: 11 (Automatic based on SIC, MAXLAG=14)

\begin{tabular}{lccc}
\hline & & t-Statistic & Prob.* \\
\hline Augmented Dickey-Fuller test statistic & -2.852071 & 0.0530 \\
Test critical values: & $1 \%$ leve1 & -3.463405 & \\
& $5 \%$ leve1 & -2.875972 & \\
& $10 \%$ leve1 & -2.574541 & \\
\hline
\end{tabular}


Null Hypothesis: D(M2G) has a unit root

Exogenous: Constant

Lag Length: 10 (Automatic based on SIC, MAXLAG=14)

\begin{tabular}{lccc}
\hline & & t-Statistic & Prob.* $^{*}$ \\
\hline Augmented Dickey-Fuller test statistic & -9.778731 & 0.0000 \\
Test critical values: & 1\% level & -3.463405 & \\
& $5 \%$ level & -2.875972 & \\
& $10 \%$ level & -2.574541 & \\
\hline
\end{tabular}

*MacKinnon (1996) one-sided p-values.

Null Hypothesis: LR has a unit root

Exogenous: Constant

Lag Length: 2 (Automatic based on SIC, MAXLAG=14)

\begin{tabular}{lccc}
\hline & & t-Statistic & Prob.* \\
\hline Augmented Dickey-Fuller test statistic & -3.541799 & 0.0078 \\
Test critical values: & $1 \%$ level & -3.461783 & \\
& $5 \%$ level & -2.875262 & \\
& $10 \%$ leve1 & -2.574161 & \\
\hline
\end{tabular}

*MacKinnon (1996) one-sided p-values.

Null Hypothesis: D(LR) has a unit root

Exogenous: Constant

Lag Length: 4 (Automatic based on SIC, MAXLAG=14)

\begin{tabular}{lccc}
\hline & & t-Statistic & Prob. $^{*}$ \\
\hline Augmented Dickey-Fuller test statistic & -10.23082 & 0.0000 \\
Test critical values: & 1\% level & -3.462253 & \\
& $5 \%$ level & -2.875468 & \\
& $10 \%$ leve1 & -2.574271 & \\
\hline
\end{tabular}




\section{Appendix-4}

\section{Auto Correlation Function}

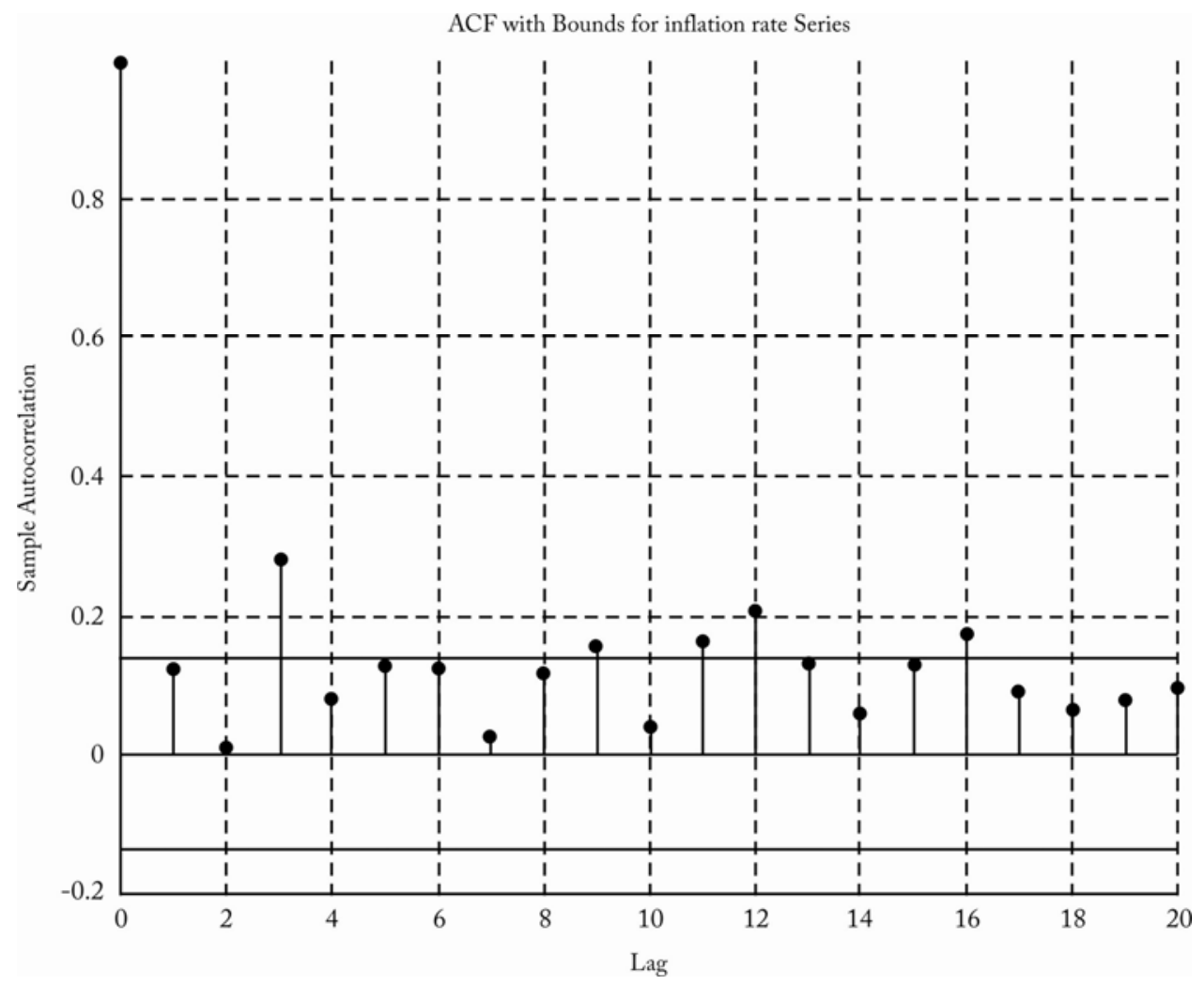

Estimating Mean Equation of ARI $(3,1)$

\begin{tabular}{lcccc}
\hline \multicolumn{1}{c}{ Variable } & Coefficient & Std. Error & t-Statistic & Prob. \\
\hline C & 0.368649 & 0.050560 & 7.291354 & 0.0000 \\
D(CPI(-3)) & 0.291906 & 0.067622 & 4.316703 & 0.0000 \\
R-squared & 0.883323 & Mean dependent var & 0.516280 \\
Adjusted R-squared & 0.778852 & S.D. dependent var & 0.558219 \\
S.E. of regression & 0.535758 & Akaike info criterion & 1.599348 \\
Sum squared resid & 58.84261 & Schwarz criterion & 1.631548 \\
Log likelihood & -163.5325 & F-statistic & 18.63393 \\
Durbin-Watson stat & 1.914153 & Prob (F-statistic) & 0.000025 \\
\hline
\end{tabular}




\section{Appendix-5}

\section{Pre Estimation of ARCH Model}

Ljung-Box-Pierce Q-Test

$\begin{array}{cccc}\mathrm{H} & \text { P-Value } & \text { Stat } & \text { C-Value } \\ 1.0000 & 0.0001 & 37.0742 & 18.3070 \\ 1.0000 & 0.0000 & 61.2245 & 24.9958 \\ 1.0000 & 0.0000 & 74.5926 & 31.4104\end{array}$

Engle's ARCH Test

$\begin{array}{cccc}\mathrm{H} & \text { P-Value } & \text { Stat } & \text { C-Value } \\ 1.00 & 0.0085 & 35.4559 & 18.3070 \\ 1.00 & 0.0053 & 48.4310 & 24.9958 \\ 1.00 & 0.0023 & 59.7615 & 31.4104\end{array}$

ARCH LM Test

ARCH Test:

\begin{tabular}{lcll}
\hline F-statistic & 0.407029 & Probability & 0.0048114 \\
Obs*R-squared & 184.547 & Probability & 0.0043918 \\
\hline
\end{tabular}

Post Estimation Analysis

The same Ljung-Box-Pierce Q-Test applies to the (innovations/sigmas) square residuals. It confirms there is no serial correlation exists.

$\begin{array}{llcc}\mathrm{H} & \text { P-Value } & \text { Stat } & \text { C-Value } \\ 0 & 0.9952 & 2.1299 & 18.3070 \\ 0 & 0.9282 & 7.8873 & 24.9958 \\ 0 & 0.9770 & 9.4581 & 31.4104\end{array}$




\section{Appendix-6}

GARCH $(1,1)$

GARCH $=\mathrm{C}(3)+\mathrm{C}(4) *$ RESID $(-1) \wedge 2+\mathrm{C}(5) * \mathrm{GARCH}(-1)$

\begin{tabular}{lcccc}
\hline & Coefficient & Std. Error & z-Statistic & Prob. \\
\hline C & 0.372052 & 0.051969 & 7.159164 & 0.0000 \\
D(CPI(-3)) & 0.253261 & 0.066743 & 3.794536 & 0.0001 \\
& Variance Equation & & \\
C & -0.001405 & 0.001250 & -1.124577 & 0.2608 \\
RESID(-1)^2 & 0.001574 & 0.000930 & 1.692335 & 0.0906 \\
GARCH(-1) & 0.912191 & 0.008365 & 120.9994 & 0.0000 \\
R-squared & 0.81023 & Mean dependent var & 0.516280 \\
Adjusted R-squared & 0.62825 & S.D. dependent var & 0.558219 \\
S.E. of regression & 0.540399 & Akaike info criterion & 1.496127 \\
Sum squared resid & 58.99029 & Schwarz criterion & 1.576627 \\
Log likelihood & -149.8491 & F-statistic & 44.52392 \\
Durbin-Watson stat & 1.920719 & Prob(F-statistic) & 0.001806 \\
\hline
\end{tabular}

Post Estimation Analysis

QQ Plot

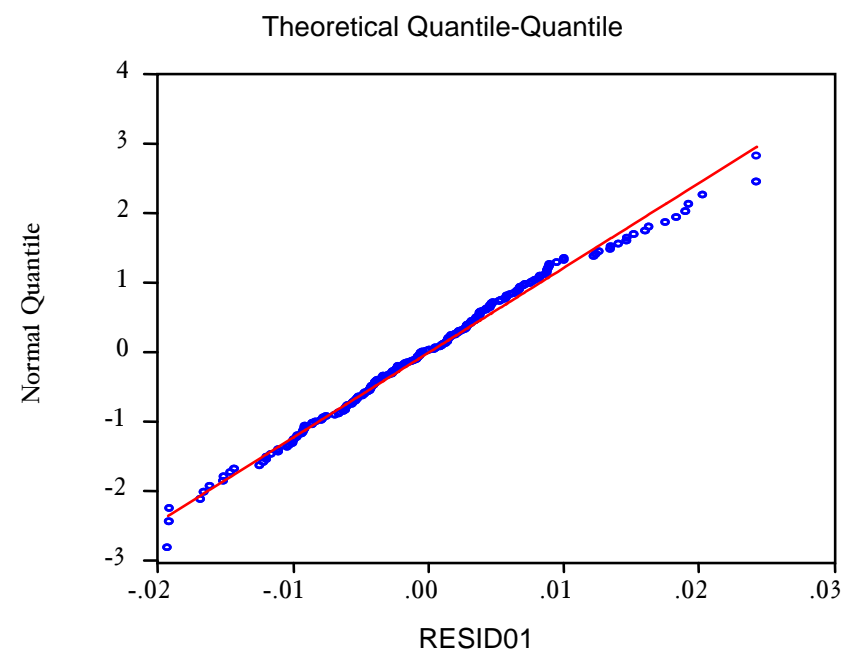




\section{Residuals graph}

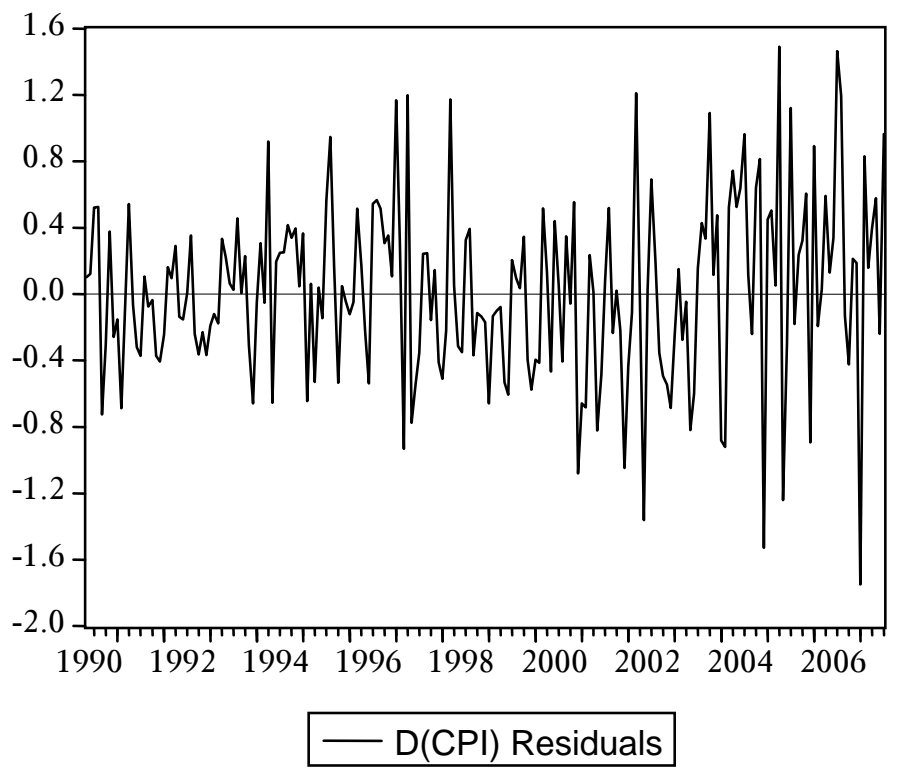




\section{Appendix-7}

\section{EGARCH MODEL}

Dependent Variable: CPI

Method: ML - ARCH (Marquardt) - Normal distribution

Date: 11/17/08 Time: 22:06

Sample (adjusted): 1990M04 2007M04

Included observations: 205 after adjustments

Convergence achieved after 122 iterations

Variance backcast: ON

LOG(GARCH) $=\mathrm{C}(10)+\mathrm{C}(11) *$ ABS(RESID $(-1) / @ S Q R T(G A R C H(-1)))+$

C(12)*RESID(-1)/@SQRT(GARCH(-1)) + C(13)*LOG(GARCH) -1)) + C(14)*D1

\begin{tabular}{ccccc}
\hline & Coefficient & Std. Error & z-Statistic & Prob. \\
\hline CM(-1) & 0.002898 & 0.015403 & 0.188173 & 0.8507 \\
CM(-2) & 0.004257 & 0.016415 & 0.259339 & 0.7954 \\
CPI(-1) & 0.628035 & 0.113507 & 5.533020 & 0.0000 \\
CPI(-2) & 0.383178 & 0.114186 & 3.355719 & 0.0008 \\
IP(-1) & -0.005942 & 0.005686 & 1.045049 & 0.2960 \\
IP(-2) & 0.004617 & 0.005125 & 0.900907 & 0.3676 \\
M2G(-1) & 0.002895 & 0.019437 & 0.148958 & 0.8816 \\
M2G(-2) & 0.017779 & 0.026466 & 0.671745 & 0.5017 \\
C & 0.059997 & 0.196759 & 0.304929 & 0.7604 \\
& Variance Equation & & \\
C(10) & -0.347193 & 0.103587 & -3.351711 & 0.0008 \\
C(11) & 0.638522 & 0.165502 & 3.858090 & 0.0001 \\
C(12) & -0.289787 & 0.110599 & -2.620162 & 0.0088 \\
C(13) & 0.974693 & 0.026978 & 36.12887 & 0.0000 \\
C(14) & -0.706747 & 0.325207 & -2.173225 & 0.0298 \\
& 0.996391 & Mean dependent var & 88.29178 \\
R-squared & 0.996146 & S.D. dependent var & 28.66141 \\
Adjusted R-squared & 1.779402 & Akaike info criterion & 2.815318 \\
S.E. of regression & 604.7580 & Schwarz criterion & 3.042255 \\
Sum squared resid & -274.5701 & F-statistic & 4056.614 \\
Log likelihood & 2.292783 & Prob(F-statistic) & 0.000000 \\
Durbin-Watson stat & \multicolumn{5}{c}{. } & \\
\hline
\end{tabular}

